\title{
Trabalho, gestão e subjetividade: dilemas de chefias Intermediárias em contexto hospitalar
}

\section{Work, management and subjectivity: dilemmas to the hospital intermediate managements}

\author{
Lílian Weber $^{1}$ \\ Carmem Ligia lochins Grisci
}

\begin{abstract}
Resumo
O presente artigo objetivou discutir os modos de vivenciar e dar sentido à experiência de gestão de chefias intermediárias de um hospital universitário público. Para tanto, foi realizado um estudo de caso no Hospital de Clínicas de Porto Alegre (HCPA), no qual participaram 23 chefias intermediárias. A coleta de dados deu-se através da constituição de um grupo, no qual se propôs uma intervenção fotográfica; de entrevistas individuais semiestruturadas; de fontes documentais; da observação direta e de conversas informais. A análise dos dados foi realizada à luz do referencial teórico, principalmente dos seguintes autores: Carapinheiro e Foucault em relação ao hospital; Campos e Mintzberg com relação à gestão; e Bauman e Hardt e Negri em relação à subjetividade. Os resultados da pesquisa indicam que não há um modo único de ser chefia intermediária no HCPA; que coexistem dois modos de gestão - público e privado - em constante tensão no Hospital; que a noção do trabalho imaterial é pertinente à realidade hospitalar e que os modos de gestão configuram dilemas às chefias intermediárias. Neste campo múltiplo e heterogêneo se produzem subjetividades e vislumbram-se possibilidades de vivências de prazer e sofrimento no trabalho.
\end{abstract}

Palavras-chave: Gestão hospitalar; chefias intermediárias; trabalho e subjetividade

\begin{abstract}
This article seeks to understand the ways of living and giving meaning to the administration experience of the intermediate managers of a public school-hospital. Research was developed through a case study at Hospital de Clínicas de Porto Alegre, in which 23 intermediate managers participated. Data was collected by forming a group, in which a photographic intervention was proposed; through individual semi-structured interviews; through documental sources; through direct observation and informal conversations. Data analysis was achieved based on the pertinent theoretical basis. The results of this research indicate that there is no unique way of being an intermediate manager at HCPA; that two administration manners coexist - public and private - in constant tension; that the notion of the immaterial work is pertinent to the hospital reality and that the administration manners form dilemmas to the intermediate managers. In this multiple and heterogeneous field subjectivities are generated and possibilities of experiencing pleasure and suffering at work appear.
\end{abstract}

Keywords: Hospital management; intermediate managers; work and subjectivity

\footnotetext{
1 Psicóloga, Mestre e Doutoranda em Administração no Programa de Pós-Graduação em Administração da Escola de Administração da Universidade Federal do Rio Grande do Sul - PPGA/EA/UFRGS. Bolsista da CAPES- Endereço: Rua Ramiro Barcelos, 1215, s. 401 - Porto Alegre/Rio Grande do Sul. E-mail: Iweber@bhzdesign.com.br

2 Psicóloga, Doutora em Psicologia pela Pontifícia Universidade Católica do Rio Grande do Sul. Professora do Programa de Pós-Graduação em Administração da Escola de Administração da Universidade Federal do Rio Grande do Sul. Pesquisadora do CNPq. Endereço: Av. Washington Luiz, 855 - Porto Alegre/Rio Grande do Sul - Brasil - CEP: - CEP: 90010-460 . E-mail: cligrisci@ea.ufrgs.br
}

Artigo submetido em outubro de 2008 e aceito em abril 2009 


\section{Introdução}

No Brasil, a prestação de serviços na área da saúde caracteriza-se, de modo geral, pela cultura hospitalocêntrica. Constata-se que o hospital, mesmo diferenciando-se em tamanho, capacidade de atendimento e grau de complexidade, tem materializado a experiência de viver a doença (SILVA, 2004; PIRES, 1998; PITTA, 1994).

Neste contexto, o hospital tem sido objeto de inúmeros estudos que envolvem: a) os pacientes, seus tratamentos e sua relação com a equipe de profissionais da saúde; b) as práticas médicas mais eficientes e eficazes; c) o controle de infecções; d) a organização hospitalar como espaço de disciplinamento, onde interatuam relações de saber-poder, saúde-doença, objetificação do paciente versus humanização da assistência. O hospital também tem sido alvo de interesse enquanto espaço de trabalho que, paradoxalmente ao seu produto (saúde), tem produzido condições potenciais de adoecimento de seus trabalhadores.

Mais recentemente, o hospital tem despertado o interesse como empresa, impulsionando estudos sobre planejamento estratégico, sistemas de informação, redução de custos. Esta perspectiva está atrelada ao contexto neoliberal, de globalização e reforma do Estado, que apresenta alta exigência por resultados positivos (lucros) para sobrevivência em um mercado competitivo. Tais estudos proporcionam visibilidade ao contexto mercantil no qual a saúde está inserida, entretanto mostram pouco sobre seu impacto no cotidiano e nos modos de trabalhar.

As características atreladas a este contexto afetam a todos os trabalhadores da área. Contudo, privilegiaram-se nesta pesquisa as chefias intermediárias que, por características inerentes à função, devem não apenas administrar de forma eficiente, como também estimular e liderar sua equipe de trabalho para mobilização frente às novas demandas. Sobre elas recai a responsabilidade pela execução do projeto de alcançar as metas determinadas.

Ao focar a atenção a este grupo de profissionais, popularmente considerados como "sanduíche", percebe-se que se trata de uma função permeada por uma complexidade que tem sido pouco explorada pelos estudos na área hospitalar. Desta forma, a pesquisa que originou este artigo objetivou ser um veículo de visibilidade ao trabalho realizado pelas chefias ${ }^{1}$ intermediárias de um hospital universitário público, buscando compreender como elas vivenciam e dão sentido às suas experiências de gestão no cotidiano de trabalho.

O referencial teórico que subsidiou a pesquisa, apresentado a seguir, abrange uma contextualização da organização hospitalar, aspectos sobre a gestão e os gerentes nestas organizações e a produção de subjetividades na contemporaneidade e no trabalho em saúde. Posteriormente, serão apresentados os procedimentos metodológicos e, em seguida, os resultados e as conclusões.

\section{O hospital e a gestão}

O hospital como instrumento terapêutico, de intervenção sobre o doente e a doença, é fato relativamente recente, se considerada sua história mais amplamente. A organização hospitalar, como conhecida na atualidade, é fruto de uma construção sócio-histórica, que envolve aspectos políticos, sociais, econômicos e do desenvolvimento científico. Seu percurso foi, e continua sendo, marcado por crises, tensões entre múltiplos interesses e neste jogo de forças a configuração do hospital tem se modificado. O hospital constituía-se como instituição religiosa de assistência, asilo para pobres e peregrinos infectados pelas pestes e passou a configurarse como espaço científico, campo fundamental da produção do saber e da prática da medicina moderna (CARAPINHEIRO, 2005; FOUCAULT, 2000).

A reorganização do hospital ocorreu através da introdução de uma tecnologia política, a disciplina, e o trabalho ali realizado foi sendo organizado segundo ditames de controle, hierarquia e poder (FOUCAULT, 2000). O disciplinamento, ainda hoje, perpassa desde o planejamento e ocupação dos espaços, via arquitetura, à possibilidade de circulação dos corpos e, principalmente, dos saberes que se instauram no hospital. Desta forma, as relações de poder (re)produzem-se mediante a definição das liberações de acesso e permanência em 
determinados locais de trabalho, descanso e lazer, bem como pode ser vislumbrada nas vestimentas, na presença e nas cores dos uniformes (SILVA, 2004; PITTA, 1994). Na atualidade, o hospital tem crescido, abrangendo diferentes serviços e especialidades em saúde, de forma que diversos autores o caracterizam como uma das organizações sociais mais complexas (CARAPINHEIRO, 2005; DUSSAULT, 1992).

O hospital é considerado como uma organização profissional ou burocracia profissional (MINTZBERG, 2003), na qual o trabalho está centrado nas habilidades e nos conhecimentos dos profissionais. Na área da saúde, o avanço do conhecimento tem impulsionado as especializações e a diversificação dos agentes responsáveis em cada especialidade. Pires (1998) afirma que nas relações entre os diversos trabalhadores no hospital foram estabelecendo-se hierarquias e que estas se cristalizam quando o organograma é organizado por categoria profissional, o que com frequiência ocorre.

Assim, a estrutura de autoridade nos hospitais é descrita como ambígua (CARAPINHEIRO, 2005), destacandose duas linhas de comando com lógicas, valores e interesses diferentes: uma, dos serviços administrativos e de suporte, voltada aos interesses econômicos, e outra, a profissional. Cecílio (2002) também fala de uma fragmentação nas linhas de comando nos hospitais entre as profissões e assinala a existência de três grandes agrupamentos: a medicina, a enfermagem e o corpo administrativo. Desta forma, tem-se que os hospitais "organizam-se segundo múltiplos sistemas de autoridade e múltiplas formas de poder profissional, cujo funcionamento exclui a referência única a um conjunto bem definido de objectivos ou a referência a uma única linha de direcção" ${ }^{2 "}$ (CARAPINHEIRO, 2005, p. 58).

Além desta perspectiva, que remete à coordenação dos grupos profissionais, também se encontram diferentes pontos de vista e interesses quando se trata de pensar a gestão dos hospitais, seu lugar no sistema de saúde, sua inserção como organização social e/ou como empresa. Estas diferenças têm sido situadas em dois polos, cada qual defendendo sua posição com argumentos que não se restringem aos critérios técnicos, mas adentram o campo ideológico, englobando diferentes visões e projetos de sociedade e cidadania.

O primeiro polo nesta discussão, atrelado ao contexto neoliberal, de globalização e reforma do Estado, segue a ideologia de mercado, imaginando como única solução para as deficiências do modelo de gestão hospitalar a sua privatização, em distintos graus e formas, e a desregulamentação dos direitos.

Para Lima-Gonçalves (2002), o hospital deve ser considerado como empresa e precisa, "indiscutivelmente", enquadrar-se nos modelos da administração empresarial com vistas à própria sobrevivência. Minotto (2003, p.39) concorda com este ponto de vista e acrescenta que dentre os vários aspectos a serem administrados destaca-se a adequada utilização dos recursos financeiros, pois "expressa os interesses de todas as partes envolvidas", que segundo ele são os acionistas, a diretoria, os funcionários e os clientes.

Os críticos a esta vertente, arguindo que os serviços de saúde fazem parte das atividades imprescindíveis para a vida em sociedade, reconhecem a saúde como direito à cidadania que, portanto, não deveria atrelar-se à lógica da privatização e comercialização. Pires (1998) identifica que o setor privado só funciona se a relação custo/benefício estiver a favor do proprietário e, portanto, os interesses dos "clientes" ficariam em segundo plano. E Campos e Amaral (2007) e Cecílio (2002) indicam que tais propostas têm privilegiado uma racionalidade instrumental e focado o gerenciamento interno dos hospitais, descuidando-se da relação destes com o sistema de saúde mais amplo.

Segue-se assim, a proposta do segundo polo nesta discussão. Esta vertente entende a saúde como bem público e considera a gestão do hospital em conexão com uma rede de atenção à saúde. Portanto, defendem as diretrizes do Sistema Único de Saúde (SUS) e avaliam que as reformas devem acontecer dentro do sistema, a partir do diagnóstico das causas de seu insucesso, pois concordam que existem problemas de eficiência e eficácia na gestão dos hospitais ligados ao SUS, atribuídos, sobretudo, ao modelo de administração burocrático-estatal.

Desta forma, todos afirmam ser necessária, seja porque é uma exigência do mercado, seja porque é um direito dos cidadãos, a operacionalização de um sistema comprometido com a qualidade no atendimento, com a superação na rigidez da gestão e com a melhor utilização dos recursos disponíveis (CAMPOS e AMARAL, 2007; CECÍlIO, 2002). Para alcançar estes resultados, as propostas da segunda vertente sugerem que se 
redefina a missão do hospital e seu perfil assistencial, sobretudo revendo a concepção hegemônica, na qual o hospital constitui-se como centro do sistema e focado na doença; que se estabeleçam indicadores; que se utilize o planejamento estratégico situacional e, sobretudo, recomendam a revisão dos organogramas e se defina uma estrutura mais horizontalizada. Campos (2005) propõe modelo de cogestão como ideal para o enfrentamento dos desafios inerentes ao trabalho nestas organizações.

\section{As chefias intermedlárlas em contexto hospitalar}

Por chefias intermediárias compreendem-se aquelas que ocupam uma posição de gerência média no organograma, em cargo de confiança, com uma remuneração extra para exercê-la. Estas chefias reportam-se a um nível superior e têm a responsabilidade de gerenciar uma área e os trabalhadores que ali atuam considerados como subordinados. Esta é uma função imbuída de status e perpassada por um discurso de autoridade, autonomia e poder. Tem-se atribuído, sobretudo no contexto atual, grande relevância ao papel do profissional responsável por realizar o gerenciamento das organizações.

Esta valorização está relacionada à grande influência que as organizações empresariais têm exercido na vida social, introduzindo um novo conjunto de valores e comportamentos, configurando uma "cultura do management", conforme Wood Jr. e Paula (2002). Segundo estes autores, "o mundo do negócio e o management passaram a moldar nossa experiência social e cultural, invadindo progressivamente os domínios da ciência e tecnologia, arte e literatura" (WOOD JR. e PAULA, 2002, p. 02). Contudo, diversos estudos têm assinalado outras perspectivas sobre esta função.

Os gerentes, segundo Strannegård (2005), são profissionais capacitados para exercer o controle, mas têm pouca ascensão sobre sua própria condição. Estão divididos entre a obediência e a resistência às demandas organizacionais. Eles encontram-se em uma situação limite de estar "quase lá" - não estão acima, nem abaixo. Estão em um "entre espaço", ou, na versão popular, "ensanduichados". Assim, encontram-se em uma posição vulnerável no que se refere à exposição ao discurso da empresa, pois o gerente intermediário exerce um papel de porta voz das políticas da empresa.

Estes profissionais são levados a uma postura de individualismo, podendo contar apenas com as próprias defesas, o que acarreta fragilidade psíquica. As chefias intermediárias não dispõem de espaços em que suas dificuldades sejam objeto de debate, de reflexão coletiva. Aliado a este fator, constata-se o medo de tornar visíveis suas próprias dificuldades e que estas sejam atribuídas à incompetência (DEJOURS, 1999). Lima (1995, p. 186) sinaliza que "o gerente quer acreditar no seu poder, na sua autonomia e se defende de uma tomada de consciência de sua real condição de sujeição, através de movimento de idealização de si mesmo". Assim, através de defesas e resistências, a organização do trabalho não logra suprimir de todo a sua autonomia. E, de fato, no trabalho em saúde, são eles os possíveis interventores nos importantes agenciamentos micropolíticos, podendo obter daí também benefícios psicológicos e materiais.

No contexto hospitalar, considerado como burocracia profissional, a inserção dos gerentes adquire contornos próprios. Nestas organizações, os profissionais do núcleo operacional (vinculados à área da saúde) controlam o próprio trabalho, bem como procuram controlar coletivamente as decisões mais amplas que os afetam. Assim, os gerentes, para exercerem seu papel, precisariam contar com o apoio dos operadores profissionais (MINTZBERG, 2003).

Este autor afirma que é comum a compreensão destas organizações sob a configuração de uma pirâmide invertida, na qual os operadores estariam no topo e os gerentes na base. Contudo, avalia que esta é uma concepção que subestima o poder dos gerentes. Este adquire relevância na medida em que é chamado a intermediar negociações, seja em definições que digam respeito à categorização do processo de trabalho e definições de responsabilidades, bem como auxiliando o grupo de profissionais a discutir seus projetos com o sistema interno e externo à organização. $\mathrm{O}$ mesmo autor afirma que esta influência vai além do auxílio aos profissionais, na medida em que procura mudar a organização em sua totalidade para torná-la mais eficaz. $\mathrm{O}$ gerente demarca um importante território ao atuar diante das dissonâncias da estrutura e possibilitar que o núcleo operacional dedique-se, com plenas condições, às suas atribuições principais. 
Outra característica relevante e específica do trabalho em contexto hospitalar é que, estar em organização hospitalar, expõe o profissional a situações de sofrimento, dor e morte e, por isto, esse tem sido considerado um trabalho penoso e insalubre (PITTA, 1994). Além disto, o trabalho nesta área apresenta o componente da impotência de estar diante de situações para as quais o profissional sente-se incapaz de interferir, da mesma forma que implica lidar constantemente com situações imprevistas. Estas características demandam um esforço intenso dos gerentes que, habitualmente, são formados ou forçados a pensar e atuar em ambientes mais circunscritos, através de planejamento e controle.

O trabalho em saúde, por suas peculiaridades, nunca foi totalmente capturado pelos esquemas da administração científica. Como trabalho imaterial, a atuação neste setor está na dependência das qualificações do trabalhador, dentre elas o domínio e a troca de conhecimento, a capacidade de lidar com imprevistos e relacionar-se com as pessoas.

\section{Trabalho, gestão e produção de subjetividades na contemporaneidade}

As sociedades têm caracterizado modos de viver influenciados pelas alterações no plano econômico que redefinem os elementos do plano social e produzem diferentes maneiras de pensar, sentir, agir, enfim, de tornar-se humano. $\mathrm{O}$ trabalho, neste contexto, apresenta-se como um "importante agente de subjetivação do homem, o que implica dizer que determinados processos de sociabilização vividos no trabalho podem se instituir como traços constitutivos do sujeito" (PASCHE, 2003, p. 75). Desta forma, mostra-se relevante conhecer suas configurações, sobretudo como é caracterizado na sociedade contemporânea.

Vive-se em uma época, conforme Hardt e Negri (2005), na qual prevalece o modelo da economia informacional. A transição para este modelo tem acarretado mudanças na percepção e vivência do tempo, marcado fortemente pela aceleração. Da mesma forma, a noção de espaço tem sido afetada (HARVEY, 1993).

Ao analisar a conformação da sociedade atual, Bauman (2003) afirma que, com o arrefecimento de uma perspectiva de futuro, as relações a longo prazo, de vínculos sólidos e duradouros, dão lugar a relacionamentos efêmeros e instantâneos. A desconcertante volatilidade social, a redução de perspectivas, a improbabilidade de assentamento duradouro, a imprecisão das regras configuram esta como uma era de incertezas. Incertezas e medo, pois em pouco tempo as coisas passam a ser consideradas inúteis e prontamente descartadas. E como acontece com as coisas, também ocorre com as pessoas. "A opção é modernizar-se ou perecer”, diz Bauman (2005, p.34).

A ameaça que paira é a de não dar conta da intensa aceleração; é o medo da incompetência, como aponta Dejours (1999). É o fantasma da inutilidade, nas palavras de Sennett (2006); é tornar-se um ser humano refugado, excessivo ou redundante, conforme Bauman (2005). Os limites que produzem e distanciam o "produto útil" do "refugo" conformam uma "zona cinzenta", onde habita a ansiedade, a indefinição e mesmo o perigo.

Por todo este panorama, Pelbart (2003, p. 20) afirma que a vida tornou-se um capital no contexto do "capitalismo em rede, conexionista, rizomático", de forma que se tornam mercadorias e são vendidas "maneiras de ver e de sentir, de pensar e de perceber, de morar e de vestir. [...] Consumimos formas de vida [...] consumimos toneladas de subjetividade". Entretanto, na compreensão deste autor, a subjetividade é uma força viva e, portanto, aparece como potente para escapar ao que ele denomina de "subjetividade vampirizada".

A possibilidade de não sujeição está ligada à ideia de que há um conjunto vivo de estratégias que resistem à massificação e à padronização. A possibilidade de invenção é uma potência do homem comum e uma forma de resistência quando se resgata a relação de cooperação, da inteligência coletiva, da possibilidade de afetação recíproca.

A invenção mencionada diz respeito a uma característica que, até pouco tempo atrás, era relegada ao domínio exclusivamente da esfera privada, a uma dimensão subjetiva e extra-econômica. Na atualidade, entretanto, essa potência passou a ser "condição geral e comum da produção" (PELBART, 2003; NEGRI, 2003). 
Hardt e Negri (2005) afirmam que a transição para economia informacional não poderia ocorrer sem uma consequente alteração na qualidade e natureza do trabalho. A economia neste paradigma gira em torno do setor de serviços que se baseia na troca de informações e conhecimentos e cuja produção praticamente não envolve bens materiais. $\mathrm{O}$ trabalho envolvido neste tipo de produção é definido como trabalho imaterial.

O trabalho imaterial envolve comunicação, criatividade, afetividade, interação humana, cooperação, demandando qualidades inerentes ao trabalhador, que extrapolam o plano do saber. A "vitalidade", através de sua força inventiva, é a fonte para a produção imaterial (PELBART, 2003). Retornam ao mundo do trabalho, então, as capacidades cognitivo-afetivas que a organização do trabalho no modelo taylorista havia praticamente excluído. Segundo Lazzarato e Negri (2001, p. 25), "é a alma do operário que deve descer na oficina".

Sendo assim, o trabalho imaterial anuncia para o trabalhador liberdades ampliadas pela redução da alienação, das fronteiras e dos espaços de confinamento. Contudo, ao realizar essa passagem, o trabalho vê-se também diante de novas e mais sutis formas de controle (GRISCI, 2006). Da mesma forma que o trabalho imaterial é inerente ao trabalhador, também a ele é destinada a responsabilidade pela consecução dos resultados e sua manutenção enquanto ser produtivo e útil. Assim, sucesso ou fracasso são compreendidos como força ou fraqueza individual (SENNETT, 2001). O trabalhador passa a atuar "em prol da rentabilização de si" (GRISCI, 2006, p. 329) e mesmo aqueles que possuem vínculo empregatício, atuam de forma "autonomizada", gestores de sua atuação.

Este modo de trabalhar implica uma impossibilidade de separar espaços de trabalho e não-trabalho, bem como a persecução de um controle indireto na totalidade de sua vida. O trabalhador gestor de si atua sob a forma de redes e de fluxos, que dependem das capacidades relacionais, comunicativas e organizativas (LAZZARATO e NEGRI, 2001).

Outra implicação do modo autonomizado de trabalhar remete à precariedade e até mesmo ausência de reconhecimento pelo trabalho realizado. Segundo Dejours (1999, p. 34), o reconhecimento "não é uma reivindicação secundária dos que trabalham. Muito pelo contrário, mostra-se decisivo na dinâmica da mobilização subjetiva da inteligência e da personalidade no trabalho". Sua relevância está na possibilidade de dar sentido ao esforço, às angústias, às dúvidas, às decepções.

\section{A pesquisa em campo - procedimentos metodológicos}

A presente pesquisa desenvolveu-se na modalidade de um estudo de caso (YIN, 2001), realizado no Hospital de Clínicas de Porto Alegre (HCPA), um hospital geral público, de direito privado, universitário, de grande porte e alta complexidade.

Os participantes eram funcionários contratados, ocupando no organograma a posição de gerência média, correspondendo na estrutura do HCPA às chefias de serviço e de seção da Vice-presidência Administrativa (VPA), e à chefia de unidade do Grupo de Enfermagem (GENF). No total, participaram 23 das 91 chefias intermediárias do HCPA, de ambos os sexos, atuando no Hospital, em média, há 12 anos. Os dados foram obtidos através de grupo, intervenção fotográfica, entrevistas individuais semiestruturadas e fontes documentais.

A aproximação ao campo deu-se, inicialmente, através do contato com as chefias intermediárias do Hospital em suas reuniões de área, quando a pesquisa foi divulgada. Encaminhou-se e-mail às mesmas, ratificando o convite à participação. Assim, as chefias intermediárias interessadas constituíram o grupo.

O grupo contou com a participação de 11 chefias intermediárias e mostrou-se como espaço privilegiado para a discussão das vivências e dos sentidos produzidos no cotidiano de trabalho dos participantes. Compreende-se, tal qual o fazem Tittoni e Nardi (2006), que na análise dos modos como os sujeitos vivenciam suas experiências de trabalho e a elas dão sentido está imbricada a relação entre trabalho e subjetividade, foco da pesquisa. A coordenação do grupo ficou a cargo da pesquisadora e conduzido seguindo questões norteadoras elaboradas a partir de estudos prévios. 
Durante os sete encontros do grupo, com duração de uma hora e meia cada um, foi proposta uma intervenção fotográfica. Tittoni e Maurent (2007) afirmam que a intervenção fotográfica é importante recurso à produção do conhecimento e sua crescente inserção na esfera acadêmica visa, justamente, reintegrar ao processo científico outras visibilidades e um pouco da sensibilidade da experiência que a racionalidade moderna esforçou-se por retirar da atividade de pesquisa. As referidas autoras salientam esta importância sobretudo pela possibilidade de evidenciar jogos de poder e processos de subjetivação. A fotografia "dá acesso a um modo inédito de ver a realidade. [...] a fotografia mostra o mundo de uma maneira invisível a olho nu, permite ver coisas normalmente não vistas" (MAURENT, 2005, p. 29).

Neste contexto, fotografar foi proposto como dispositivo para refletir sobre o próprio trabalho, pelo exercício de responder, através de fotografias feitas no espaço do hospital, à seguinte questão: "como é ser chefia no HCPA?". A produção das fotografias (66, no total) foi discutida no grupo e permitiu o debate sobre o tema a partir de olhares de estranhamento ao cotidiano naturalizado ${ }^{3}$.

Além do grupo, também foram realizadas entrevistas individuais semiestruturadas. Estas entrevistas foram feitas com outras 12 chefias, que não haviam participado do grupo. As entrevistas foram norteadas por um roteiro, elaborado a partir dos tópicos levantados e discutidos no grupo.

Outros dados foram obtidos a partir da pesquisa em fontes documentais, como relatórios dos processos de trabalho e de gestão, disponíveis no sistema informatizado do Hospital, e observações no cotidiano. As múltiplas fontes constituíram-se como oportunidades de estar no Hospital e em contato com o objeto da pesquisa, permitindo um olhar a partir de diferentes perspectivas e a ampliação da possibilidade de compreensão do tema.

Os dados foram submetidos à análise conforme proposição de Minayo (2001), que prevê a ordenação, a classificação e a análise final dos dados à luz da teoria pertinente. No que se refere ao hospital, as análises foram fundamentadas principalmente nos seguintes autores: Silva (2004); Carapinheiro (2005); Mintzberg (2003); Foucault (2000). Com relação à gestão, utilizou-se os seguintes referenciais: Carapinheiro (2005); Campos (2005); Campos e Amaral (2007); Mintzberg (2003); Cecílio (2002). E as análises acerca da produção de subjetividades embasaram-se em: Dejours (1999; 2004); Harvey (1993); Hardt e Negri (2005); Pelbart (2003); Sennett (2001; 2003) e Bauman (2003; 2005; 2007).

Ao final do trabalho de análise, o material elaborado foi debatido com o grupo de chefias intermediárias composto inicialmente, em um processo de validação. $O$ resultado deste trabalho é apresentado a seguir.

\section{Apresentação e anállse dos resultados}

\section{Vivências e sentidos da experiência de gestão de chefias intermediárias no HCPA}

O HCPA, desde que começou a ser planejado, conforme consta em seus relatórios, foi marcado pelo compromisso de ser um referencial público de alta confiabilidade em saúde, sustentado em três pilares: a assistência, o ensino e a pesquisa, o que tem implicações nos modos de gestão e repercussão no trabalho das chefias intermediárias.

Acompanhando os avanços científicos e as mudanças tecnológicas na área da saúde, a estrutura e a produção do Hospital foram se alterando ao longo dos anos, observando-se crescimento do espaço físico e da capacidade instalada de atendimento, bem como a incorporação de novas áreas de atuação e especialidades. As mudanças buscaram acompanhar as inovações em equipamentos, em informática e na prestação da assistência em saúde. Para atender a este projeto organizacional, o HCPA conta atualmente com cerca de quatro mil funcionários, sendo seu quadro diretivo (Administração Central) composto pela presidência, uma vice-presidência médica (VPM), uma administrativa (VPA) e de enfermagem (denomina-se Grupo de Enfermagem - GENF, mas tem status de vice-presidência). Na VPM, subordinados ao vice-presidente estão os chefes de serviço, que são, em geral, professores da Universidade Federal do Rio Grande do Sul (UFRGS). O mesmo acontece no GENF, onde à coordenadora estão subordinadas $a^{4}$ chefes de serviço, também professoras da UFRGS. Seguem-se às 
chefes de serviço as chefias de unidade, enfermeiras que atuam também na assistência direta aos pacientes. Na VPA, o vice-presidente é seguido no organograma por coordenadores, aos quais seguem os chefes de serviço e, em seguida, os chefes de seção. Tem-se, portanto, como chefia intermediária para os propósitos da pesquisa realizada, os chefes de serviço e seção da VPA e as chefias de unidade do GENF. Este panorama exemplifica a estrutura hierárquica descrita no referencial teórico como típica aos hospitais.

O HCPA faz parte do conjunto de hospitais universitários vinculados ao Ministério da Educação (ME), entretanto, desde seu início, conta com uma natureza jurídica diferenciada: é um hospital público de direito privado. A natureza jurídica mista lhe proporciona maior autonomia e flexibilidade, se comparado aos hospitais públicos. Por ser um hospital público de direito privado, as chefias intermediárias entendem que coexistem, antagonicamente, propostas de mercado, de racionalização e agilidade com um "ranço de instituição pública", sobretudo na existência de critérios políticos e não técnicos para a tomada de decisão.

No que tange à gestão pública, os participantes da pesquisa avaliam o SUS. Segundo eles, o sistema apresentase "desorganizado" no que se refere à hierarquização da prestação de serviços. Isto se revela pelo volume de atendimentos prestados a pacientes com problemas de saúde de baixa gravidade ou situações crônicas, que deveriam ser acompanhados em Unidades Básicas de Saúde, conforme a compreensão do SUS estruturado em níveis de complexidade, restringindo a possibilidade de atenção aos usuários com enfermidades mais graves. A questão para as chefias intermediárias está no gerenciamento destas situações e no redirecionamento destes atendimentos. Estas questões sobrecarregam o cotidiano das chefias intermediárias, pois demandam constantes intervenções, e elas se questionam: "quem é responsável por isto, o Hospital ou o gestor maior [do sistema de saúde]?”

Ainda assim, os participantes da pesquisa consideram que o Hospital, de modo geral, realiza de forma adequada seu papel, respeitando a universalidade do acesso e prestando um atendimento de qualidade. Desta forma, afirmam que o SUS, tendo como referência o HCPA, tem a melhor prestação de serviço em saúde, para quem o acessa, oferecendo atendimento e medicamentos gratuitamente.

Se a percepção em geral é a de que o Hospital presta uma assistência de qualidade, também concordam que, na busca constante pela excelência, existem gastos desnecessários. Algumas chefias intermediárias afirmam a precariedade do sistema de gestão, observando muitos desperdícios. Em algumas questões não lhes parece ser "má fé", mas atos justificados pela solicitude e por um entendimento de que à esfera pública não caberia preocupação com restrição à abundância. Assim, uma percepção corrente entre as chefias intermediárias é de que "nunca faltou nada" no Hospital e profissionais que atuam ou têm contato com outros hospitais afirmam: "o HCPA é uma ilha da fantasia".

Contudo, as chefias intermediárias notam que está havendo uma mudança, uma "abertura para o mundo 'lá fora", conforme debatem no grupo, mobilizados pela fotografia (Fotografia 1) de um dos participantes, que procurou mostrar "a ligação com o externo" (a visão do exterior pela janela). Esta ligação foi considerada no grupo como importante fonte de conhecimento e trocas, tanto em termos de equipamentos, representados simbolicamente pela incubadora, quanto nos modos de trabalhar e gerenciar. Este é um discurso que tem sido enfatizado, com intuito de reforçar as propostas de mudanças. 


\section{Fotografia 1 - Relação com o externo: possibilidades e barreiras}

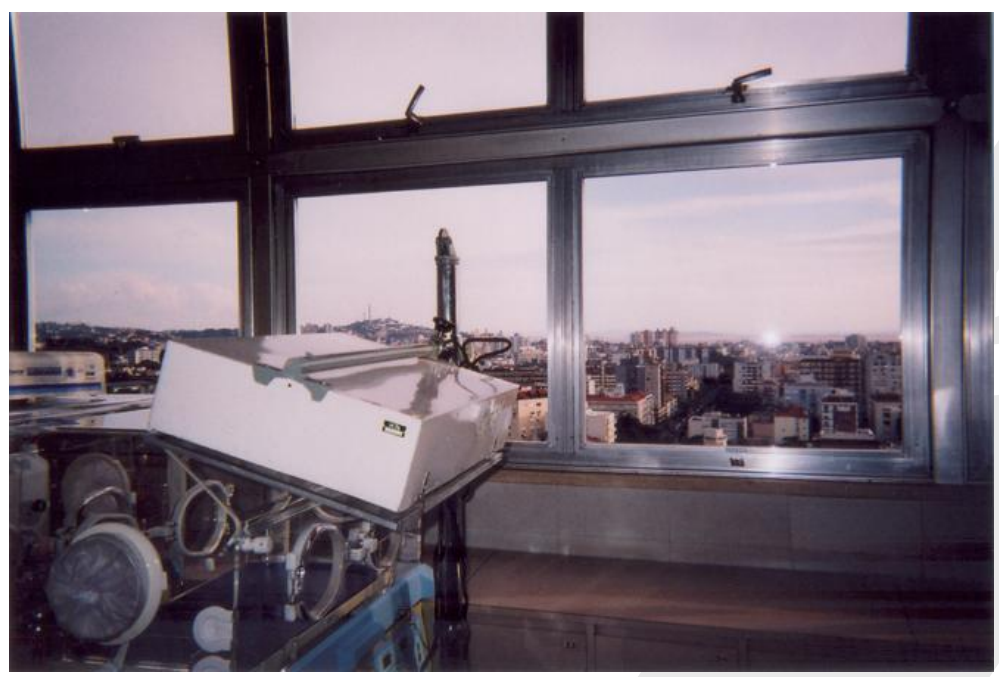

Fonte: Fotografia de participante da pesquisa

Nas palavras de uma chefia entrevistada, "aqui tem uma cultura de uso, de desperdício. Mas acho que aos poucos, com o planejamento estratégico, com o próprio plano de cargos, tudo isso vem a somar para que as pessoas fiquem mais responsáveis pelo resultado. As pessoas, de um tempo para cá, estão se movimentando um pouco mais, estão sendo conduzidas a um processo de mudança... é bom para uns e não tão bom para outros, porque tudo gera uma ansiedade e uns sabem lidar melhor do que outros... acho que é o caminho e as pessoas têm que se adaptar!". A percepção do hospital como negócio tem implicado uma desestabilização de configurações previamente estabelecidas no HCPA.

A condução dos processos de mudança tem sido atribuída à Administração Central (AC), considerada a responsável pela implementação destas tendências. Entretanto, no HCPA travam-se embates entre projetos inovadores e restrições legais, na duplicidade de sua condição jurídica mista; travam-se confrontos entre uma perspectiva que visa à implementação de modelos "modernos" de gestão e uma cultura que tende a resistir. As chefias intermediárias vivenciam esta dicotomização e expressam esta vivência como se estivessem no "meio de um redemoinho".

A adaptação a um modelo mais "profissional" de gestão, adotado pela $\mathrm{AC}$, agrada a algumas chefias intermediárias, sendo considerada como um avanço: "estamos bem próximos do auge no que há de mais moderno em administração". Para outras, as alterações no mercado tornam a adaptação do Hospital inevitável, pois "há a preocupação com a sua sobrevivência". E algumas chefias acompanham os movimentos de mudanças na gestão com preocupação, pois assistem à perda de algumas conquistas, à fragilização e flexibilização das relações, não somente entre as pessoas, mas destas com a própria organização.

De uma maneira ou de outra, as chefias intermediárias estão sendo chamadas a ocupar um lugar de destaque no movimento da organização. Sendo assim, este espaço é simbolicamente representado, por elas, através de uma "cadeira" e "sentar nela envolve muita responsabilidade". E constitui-se como um espaço individual e rotativo: senta um de cada vez. Esta representação indica a permanência no Hospital de uma estrutura de poder conforme a racionalidade gerencial hegemônica, em que a disciplina, o controle e o autoritarismo são as bases, diferenciando-se de propostas no sentido mais coletivo da gestão, ou de cogestão, conforme assinalado por Campos (2005).

No caso das chefias participantes desta pesquisa, a referida cadeira está colocada em posição singular, intermediária, que particulariza sua atuação. As dificuldades da função, em sua condição intermediária, estão atreladas ao fato de serem "elos". Os participantes desta pesquisa analisam que precisam absorver as cobranças dos superiores, com as quais nem sempre concordam, e não transferir ao seu grupo de subordinados em sua plenitude. Como as chefias intermediárias são as que mais se aproximam do nível operacional, recai sobre elas 
a requisição de "operacionalização das estratégias", ou seja, colocar em prática as demandas da organização e fazer circular um discurso produtor de sentidos, conforme interesses da organização.

Apesar disto, ou justamente por isto, a maioria das chefias intermediárias desta pesquisa percebe-se como sendo essencial na organização e constatam gratificações nesta função. Como analisa Lima (1995), se os gerentes estão nesta função é porque retiram benefícios tanto materiais quanto psicológicos. A posição ocupada não os torna vítimas, mas delineia contornos próprios. Há, portanto, como dizem as chefias, "muitas coisas positivas no nosso trabalho".

Desta forma, entendem que nesta função conseguem fazer alguma diferença. Analisam que têm maior possibilidade de participação e de entender a organização de uma forma mais ampla, fornecendo novos sentidos ao trabalho. As chefias intermediárias entendem que esta avaliação tem relação com características particulares do HCPA, pois consideram que têm muita liberdade para pensar e para fazer, sobretudo quando se comparam a profissionais em funções semelhantes em outros hospitais.

A referida liberdade é cerceada, entretanto, pelos contornos que adquirem as suas interações com seus superiores e com seus subordinados. Ao analisar a relação com seus superiores, as chefias intermediárias referem-se principalmente aos gestores da $\mathrm{AC}$ e não aos seus superiores imediatos. Compreende-se esta situação como a vinculação com quem, na atual gestão, realiza o planejamento e a definição das estratégias, isto é, são aqueles que determinam as ações das chefias intermediárias.

As opiniões sobre a relação com os superiores dividem os participantes da pesquisa. Entra em discussão aspectos como o modelo de gestão adotado; a abertura à interação e negociação; a centralização ou a delegação de autonomia. Contudo, os participantes da pesquisa concordam que é baixo o reconhecimento e pouca a valorização de seu trabalho.

Partindo desta avaliação, as chefias intermediárias consideram que atuam de forma distinta com seus subordinados. Afirmam que buscam constantemente valorizá-los, reconhecendo sua importância, pois "são eles que fazem o trabalho acontecer". Desta forma, as chefias assinalam que se preocupam com as condições de trabalho e com o bem-estar dos mesmos. Percebem que gerenciá-los envolve muita responsabilidade.

As chefias intermediárias no Hospital, além das relações hierárquicas formais estabelecidas com superiores e subordinados, vivenciam uma importante disputa de espaço e poder com a corporação médica, fato reconhecido na literatura e na prática. No HCPA, as chefias intermediárias constatam a especificidade desta relação, que é vivenciada de forma diferenciada entre aqueles que atuam mais próximos ou mais distantes da assistência, bem como entre as chefias da VPA e do GENF, pelas características do campo de atuação em cada área.

Algumas chefias, embora reconheçam as resistências por parte dos médicos às suas propostas, consideram-nas "resistências normais", tendo em vista que "o hospital é um espaço médico". Assim, consideram como sendo um papel de cada chefia conquista do seu espaço e do respeito, um trabalho construído aos poucos, com sutileza. Contudo, outras chefias pontuam a existência de grandes dificuldades na proposição de projetos, que esbarram no envolvimento da equipe médica.

As dificuldades assinaladas são atribuídas, pelos participantes da pesquisa, ao fato de que os mesmos não se mostram comprometidos com o Hospital como organização, agindo como se as metas administrativas não lhes dissessem respeito, demonstrando uma dissociação entre gestão e assistência. Permeia esta compreensão a relação de poder estabelecida e uma percepção de desqualificação, por indiferença, da ação das chefias intermediárias. Os participantes afirmam, contudo, que os profissionais médicos mais jovens já estão "com outra cabeça", conferindo importância aos processos administrativos e apresentando maior disponibilidade para "colaborar". Estes médicos parecem já terem entrado, como diz Carapinheiro (2005), na "era do administrador".

As dificuldades assinaladas na relação com a área médica são, como mencionado anteriormente, comuns e têm sido estudadas por diversos autores, em diferentes hospitais. Na presente pesquisa, é relevante destacar que se identificou uma peculiaridade: o fato de ser mais fácil para os participantes expressarem suas dificuldades na relação com o corpo médico que mencionar as dificuldades existentes entre colegas de trabalho, da mesma área 
de atuação, também chefias. Tem-se, portanto, que as relações das chefias intermediárias apresentam possibilidades e tensões diante dos superiores, dos subordinados, da classe médica e diante de seus pares. Contudo, constata-se a visibilização do conflito entre os diferentes e sua invisibilização entre os iguais, como uma estratégia que os permite enfrentar o cotidiano.

A relação estabelecida entre pares (chefias intermediárias) é permeada por dificuldades que se relacionam à competição e ao individualismo. Dois aspectos são destacados na configuração destas relações: a departamentalização do Hospital e o uso do e-mail como ferramenta de controle. Com relação à departamentalização, esta é uma característica típica dos hospitais, organizados em torno das diversas especialidades profissionais, favorecendo o comando paralelo e não complementar (CAMPOS e AMARAL, 2007). Os participantes da pesquisa afirmam que há "boa vontade, cada um quer fazer o seu trabalho da melhor forma possível, mas não conseguem ver além do seu setor, entender que o processo do Hospital é algo maior e que as áreas dependem umas das outras”. Assim, colegas deixam uns aos outros em situações de difícil resolução no que tange ao andamento dos processos.

Neste contexto, e-mail tem sido utilizado como uma ferramenta vivenciada como coercitiva e ameaçadora. As mensagens são enviadas "com cópia" para as instâncias superioras, gerando situações de mal-estar e exigindo autocontrole constante, pois, afirmam os participantes da pesquisa, "a pessoa deve estar sempre em alerta", defendendo-se das questões que estão na iminência de surgir.

Os aspectos apresentados permitem uma reflexão sobre os encontros e desencontros nas relações de trabalho das chefias intermediárias no HCPA. Neste sentido, as chefias intermediárias foram assinalando que os principais contatos estabelecidos, as redes de apoio não são as formais, mas aquelas que constituem em paralelo. A fotografia de um dos corredores do Hospital, feita por um dos participantes do grupo, apoiou este debate.

\section{Fotografia 2: Relações de passagem}

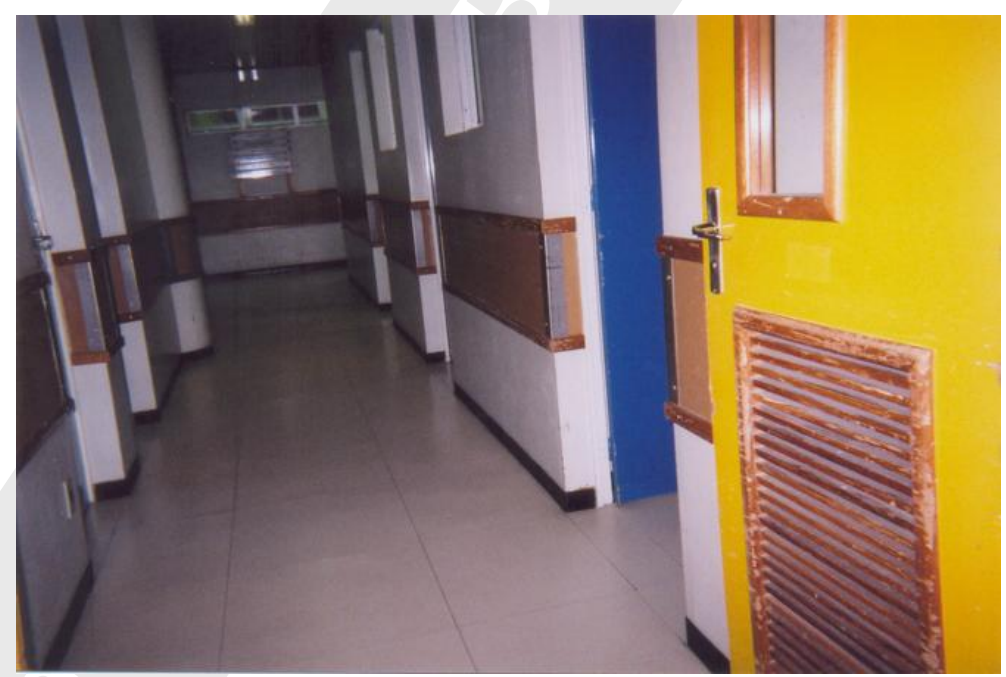

Fonte: Fotografia de participante da pesquisa

Os corredores conformam o grande labirinto em que se constitui a construção do hospital. Também representa o espaço público, o mais democrático, por onde todos passam, na mesma condição de ir e vir. Segundo Silva (2004), o diálogo nos corredores decidem, informam, criam territórios e desterritorializam com espantosa rapidez. No corredor pulsa a potência de construções subjetivas. Possibilitam-se novas rotas e linhas de fuga, um espaço de criatividade e inventividade.

Estas redes, nas organizações centralizadoras, tendem a ser ocultas, consideradas como desvios. Por isto acontecem no corredor e a possibilidade de que aconteçam revelam-se como imprescindíveis para os sujeitos nelas envolvidos. No HCPA, estas relações são percebidas como essenciais para "sobrevivência" no trabalho. 
As relações estabelecidas são particularizadas por características do contexto hospitalar, complexo e que envolve sofrimento desde o seu objeto de trabalho. Mesmo as chefias intermediárias que atuam mais distantes da assistência vivenciam o cotidiano da doença e da morte. Assim, as decisões são carregadas por esta realidade e permeadas pelo "fantasma da culpa": "já pensou se eu não liberar e o cristão morrer?"; "pode dar prejuízo, mas não sou eu que vou dizer não! Pode dar o medicamento, o equipamento. Pode fazer o procedimento. Pode...". Estas chefias expressam a convivência com uma pressão constante: "a gente tem que acertar sempre!".

A função de chefia mostra-se carregada de tensões, a começar pela tomada de decisão. $\mathrm{O}$ que deveria ser corriqueiro, pela constância, revela-se às chefias intermediárias como uma fonte constante de incertezas. $\mathrm{E}$ a decisão envolve riscos. Quase não há rotina. Tal fato atrela-se à realidade hospitalar, seu objeto de trabalho e às imprevisibilidades que o cercam. Os riscos são relativos, na maioria das vezes, a decisões administrativas para atender às questões assistenciais. As lacunas não cobertas pelo sistema formal de regras constituem-se como espaços de intervenção das chefias. Algumas vezes, além de não haver um procedimento estabelecido, existe alguma norma impeditiva da realização destas ações.

Esses momentos configuram-se como dilemas, nos quais as chefias encontram-se diante de opções difíceis e mutuamente excludentes. Elas dizem: "se a gente faz é culpado, se não faz, também! Então eu sempre penso no que vai ser melhor para o paciente". Em sua percepção, qualquer opção feita fora do padrão (o que é muito comum no contexto de imprevisibilidades) responsabiliza individualmente a chefia: "ninguém vai chegar para ti e dizer que tem que fazer isto. Ninguém. Mas se não fizer, o paciente vai ser prejudicado e quem vai ser responsabilizado somos nós". Com pouco suporte, as chefias intermediárias encontram-se em uma zona de vulnerabilidade e experimentam medo e sentimento de culpa. Algumas destas situações já estão naturalizadas no HCPA, sendo realizadas com um consentimento informal, instituído, mas velado. Ainda assim, quando a situação impõe-se diante deles, o sofrimento mobilizado é intenso.

Desta forma, constata-se a presença da incerteza no cotidiano das chefias intermediárias do HCPA. À incerteza despertada pelo ato de decidir, soma-se a incerteza sobre como esta decisão será percebida, qual repercussão provocará, em especial no que diz respeito à maneira como a chefia será avaliada por sua decisão. Assim, vivenciam sua função como instável. Como dizem, "não são chefias, mas estão chefias". A apreensão não se dá por um possível desligamento do Hospital, fato pouco comum seguindo traço de empresa pública, mas pelo receio de ser "colocado na geladeira", pela restrição da esfera de atuação e cerceamento da autonomia.

No HCPA, as chefias intermediárias constatam, ainda, que é relevante estar "sintonizado no que acontece", sendo que os modos de relacionamento constituem-se como viabilizadores do próprio trabalho, o que remete à noção de trabalho imaterial. A frustração nesta esfera advém quando não há corresponsabilidade, situação traduzida pela fala: "quem faz, leva sempre na cabeça". À sobrecarga de trabalho e à maior exposição, soma-se, como fator de frustração para aqueles que se comprometem efetivamente, a ausência de um reconhecimento pela atuação diferenciada: "quem faz ‘feijão com arroz' ou quem faz 'feijão, arroz, bife e sobremesa' recebem e é a mesma coisa".

Estas frustrações associam-se e ampliam-se em um contexto em que há sobrecarga de trabalho. A hipersolicitação é uma característica da contemporaneidade, mas o efeito produzido não é o questionamento pelo volume de trabalho, mas aparece em destaque o questionamento sobre a própria competência diante da vivência de não darem conta de tudo. E isto não apenas durante a jornada de trabalho, mas a extrapola, mobilizando as chefias intermediárias "30 horas por dia", conforme o slogan de um banco, no qual se apoia uma chefia em sua produção fotográfica. 


\section{Fotografia 3: “O dia de 30 horas"}

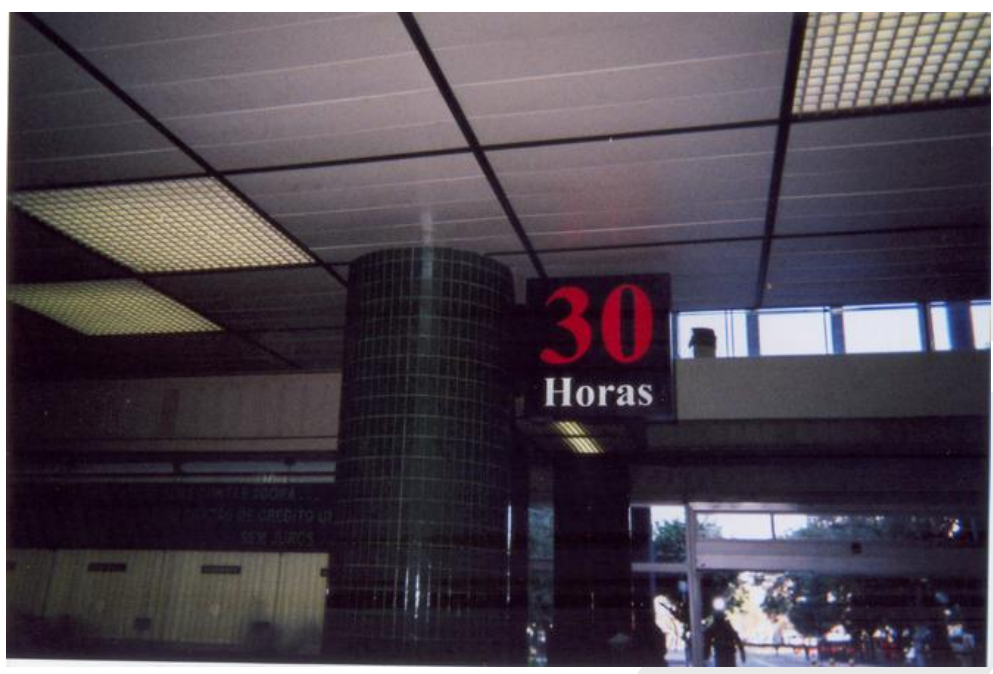

Fonte: Fotografia de participante da pesquisa

As chefias afirmam que, com frequência e com relutância, levam trabalho para casa, seja em forma material ou sob a forma de preocupação, sendo comum o relato de perder o sono ou sonhar com questões referentes ao trabalho. Para amenizar esta situação, muitos recorrem ao uso de medicamentos. Esta prática revela o adoecimento dos sujeitos mediante um trabalho que, tal qual está organizado, apresenta poucas possibilidades de estabelecimento de estratégias mais efetivas para lidar com o sofrimento que lhe é inerente. Como já se disse, o trabalho em saúde tem sido considerado insalubre e, no caso das chefias intermediárias, aliado às características do trabalho em saúde as que são pertinentes à função. Ao ocupar um cargo de gerência intermediária, estão em posição mais vulnerável ao discurso da empresa, uma posição de maior isolamento (a cadeira da chefia) e de competição, restringindo a possibilidade de vínculos e redes de solidariedade. E lidar com as adversidades tem sido apontado como mais uma das competências exigidas ao trabalhador gestor de si.

A gestão de si é uma das habilidades requisitadas e que se instala como obrigatória no contexto da instabilidade. As chefias intermediárias têm sido convidadas a não se considerarem mais como funcionários do Hospital, mas como "sócios". Desta forma, todo seu potencial é requisitado e assim há um esforço "[...] em corresponder da melhor forma possível às expectativas da empresa, oferecendo a ela o melhor de si mesmo" (LIMA, 1995, p. 163). E é a si mesmos que passam a oferecer de acordo com a lógica demandada do trabalho imaterial. Esta situação se explicitou na pesquisa através das fotografias, nas quais as chefias fotografaram a si mesmas, manifestando o desejo de visibilização e revelando a importância do reconhecimento como trabalhadores e sujeitos, indissociáveis.

Assim, "o jeito de cada um", que aparece no produto de seu trabalho, também é colocado nos seus espaços de trabalho. É no microespaço que marcam sua singularidade. São os objetos nas mesas, os quadros escolhidos, a disposição dos móveis no ambiente que possibilitam a expressão de crenças, afetos, ideologias. Mas, ao mesmo tempo em que as chefias intermediárias transferem um pouco de si ao trabalho, também são afetadas pelas expectativas da organização, conformando os modos de ser das chefias intermediárias. Conformar-se ao perfil esperado requer um aprendizado constante e também flexibilidade para mudar de acordo com a visão da $\mathrm{AC} \mathrm{e}$ das diretrizes do momento. Porém, isto implica também abdicar alguns valores pessoais: "eu infringi uma parte que é minha... isso me incomoda um monte!".

Percebe-se, portanto, a presença e a potência de linhas e forças de determinação e contingência dos desejos (PASCHE, 2003). Os fluxos e caminhos vão sendo de certa forma determinados. Não com contornos intransponíveis, mas através de indicações sutis do traçado a seguir. O trabalho das chefias intermediárias abrese a diversas interfaces, configurando-o múltiplo, heterogêneo e interdependente. Neste contexto, a ambivalência é uma constante. A atuação no Hospital realça esta vivência, mobilizando sentimentos que se 
ligam à vida de outros. Desta forma, identificam uma sensação de que estão sempre em falta; no seu trabalho infindável nada parece estar se construindo.

As chefias intermediárias elencam uma série de dificuldades, que constituem insatisfações. Afirmam que a função de chefe exige maior dedicação e responsabilidade, o que as situa em posição de maior exposição e que a gratificação salarial é pouco compensadora. Diante do questionamento, "por que ser chefia?", surge o desabafo: "nosso dia-a-dia aqui dentro do Hospital não é fácil. A gente tem que ter uma força, tirar 'lá do pé'... a gente sai triste daqui por não conseguir fazer muitas coisas... mas também saímos alegre com a sensação do dever cumprido, quando conseguimos realizar e ver os resultados acontecendo... ter o agradecimento das pessoas, a carinha dos pacientes...".

As chefias intermediárias reconhecem que no Hospital têm a possibilidade de criar, identificam a abertura para novas possibilidades em um campo sempre em expansão. A função de chefia intermediária lhes possibilita conhecer melhor a realidade organizacional, ter um pouco mais de poder e, consequentemente, ter voz mais ativa, de forma a sentirem-se mais úteis. Conseguir implementar projetos de melhorias é vivido como sucesso. Além disto, gratificam-se quando se dão conta de que estão deixando uma marca, fruto de seu trabalho. Esta gratificação potencializa-se se acompanhada do reconhecimento, sobretudo, de seus subordinados que, segundo os participantes, são as pessoas que estão mais próximas e com quem constituem, ou almejam constituir, um grupo.

Desta forma, constata-se que as chefias não se prendem em uma rede de determinações imutáveis, mas apresentam uma força criadora (PASCHE, 2003). Uma das fotografias revela esta condição.

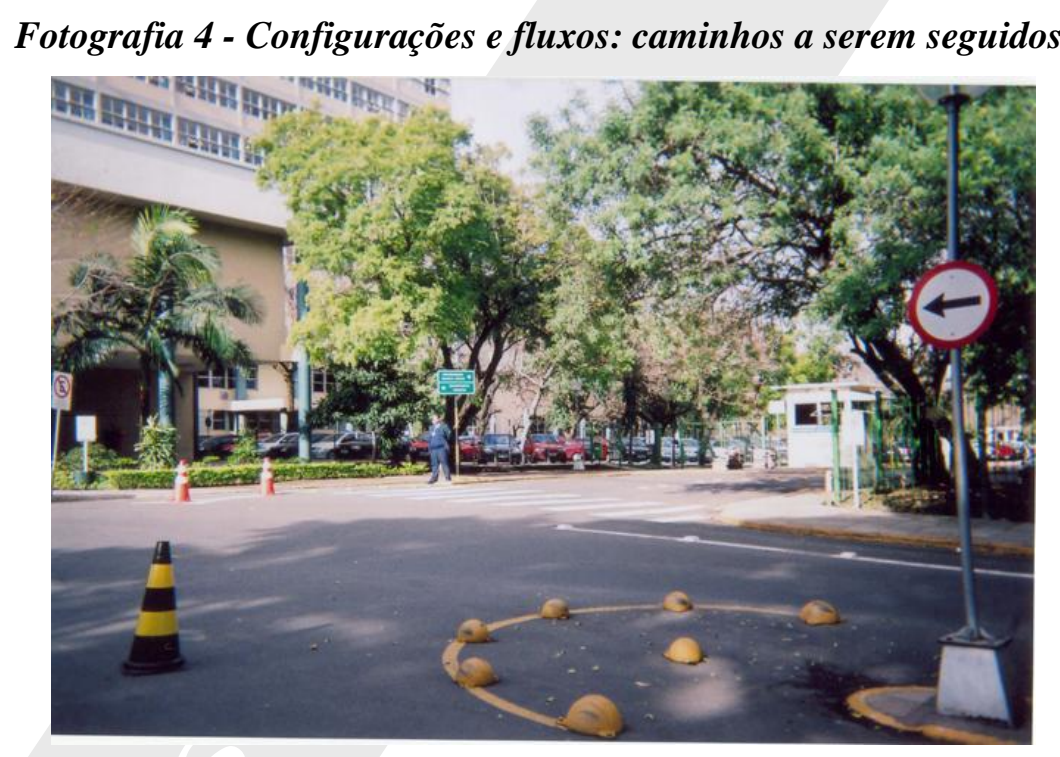

Fonte: Fotografia de participante da pesquisa

$\mathrm{Na}$ fotografia acima observa-se um conjunto de sinais indicativos de percursos: a placa indicando a direção, o vigilante que permite ou não o acesso, a placa de proibido estacionar, os cones, a pintura do asfalto. Os sinalizadores na fotografia advertem o que fazer, o que não fazer, mas não se constituem como barreiras intransponíveis. Há certa porosidade. Há possibilidade de rearranjos. O mesmo se dá com a prática das chefias intermediárias em questão.

É possível que o desejo se mova e produza outros modos de ser e viver no trabalho. A vivência da função de chefia intermediária se revela múltipla; a forma como cada chefia intermediária se "instala em sua cadeira" é muito particular, singularizando-a, e comporta tanto sofrimento como prazer. 


\section{Conclusão}

As chefias intermediárias no HCPA não se constituem como um bloco homogêneo, mas como uma pluralidade em seus modos de trabalhar e de ser. A expressão de tal pluralidade advém da própria dinâmica dos serviços de saúde que, no HCPA, faz atuarem dois modos de gestão: público e privado. Frente às atuais políticas de saúde, estes dois modos antagonizam a defesa do Sistema Único de Saúde e a tendência neoliberal de privatização da saúde, conformando as especificidades da função, as relações estabelecidas e os conflitos das chefias intermediárias.

A dinamização das políticas de saúde acarretou mudanças constantes no HCPA e coube à Administração Central o papel de propulsora da implementação de tendências nem sempre compreendidas ou experimentadas de modo tranquilo pelas chefias intermediárias, pela duplicidade da sua condição jurídica mista, na qual se travariam embates entre projetos inovadores e restrições legais; entre a avaliação de competências e a utilização de critérios políticos para designação de cargos e funções. A privatização da saúde associada ao lucro, não se sustenta nos discursos e práticas feitos no Hospital. A privatização vincula-se a uma "modernização administrativa" entendida como necessária à sobrevivência do hospital-empresa.

As chefias intermediárias posicionaram-se de diferentes modos diante deste panorama. O modelo agrada àqueles que o consideram como um avanço, reflexo da modernidade, sinal de competência. E desagrada àqueles que o percebem como produtor de novas tensões e pressões a serem experimentadas diretamente no cotidiano do trabalho.

A dinâmica que ilustra tensões cotidianas dos modos de trabalhar e de ser das chefias intermediárias diz respeito a um jogo de poder/saber que envolve antigo e novo, tradição e inovação, ditos e não ditos. Os contrastes dão a entender que a compreensão dos fazeres no hospital não tem o mesmo alcance para as chefias intermediárias em geral. A dicotomia aparente nos contrastes prevalece na condução do trabalho diário atender muitos pacientes sem qualidade ou poucos com qualidade - na forma de dilema.

Desta forma, as chefias intermediárias são colocadas e colocam-se, metaforicamente, entre "a cruz e a espada", entre o "o mar e o rochedo". Vivenciam, assim, sentimentos de vulnerabilidade e ambivalências. A vulnerabilidade atrela-se às decisões tomadas, pelo modo como podem vir a repercutir na assistência à saúde. Atrela-se, igualmente, à função exercida, não apenas pelo receio do rebaixamento concreto, mas também pelo que opera no plano simbólico do cerceamento da autonomia.

A ambivalência mostra-se presente o tempo todo. As dimensões que percorrem as atividades das chefias não são excludentes, mas interdependentes. O dilema imputa alternativas do "ou isto, ou aquilo", implicando escolhas e riscos.

A condição intermediária das chefias em questão mostra que o jogo de forças principal não é o que se trava entre superiores e subordinados, na hierarquia formal. Nestas relações encontram-se porosidades por onde é possível circular. O "ensanduichamento" destas chefias intermediárias situa-se na coexistência das lógicas público e privada que perpassam todo seu saber-fazer. Ainda que a flexibilização da organização do trabalho não tenha se instalado - e não se sabe se chegará a instalar-se - ela se anuncia de tal forma que desestabiliza os modos conhecidos de se situar frente às demandas do trabalho. Sobretudo porque estas demandas passam a convocar, cada vez mais, a implicação de si.

O cotidiano das chefias intermediárias caracteriza-se como trabalho imaterial, através do qual "o jeito de cada um" torna-se instrumento de trabalho, que deve ser moldado pelas determinações e linhas de força contingenciadas pelo hospital. A subjetividade no trabalho é a própria essência que se coloca em movimento em nome da produção do serviço e de si. Tal qual apontado por Lazzarato e Negri (2001), o trabalho imaterial requer habilidades comunicativas, relacionais e organizativas, pois se dá, sobretudo, em redes e fluxos. Esses aspectos da subjetividade a serviço do trabalho sustentam a difundida lógica da rentabilização de si.

As subjetividades em produção combinam linhas de influências de estarem num hospital universitário com características de organização mista público-privada, as determinações da função de chefia intermediária e 
ainda às influências das características da sociedade contemporânea, marcada pela aceleração do tempo, pela fragilidade das relações e pelas incertezas, dentre outras. Os modos de trabalhar e ser das chefias intermediárias estão sob estas influências, que os caracterizam sem, no entanto, defini-los como uma totalidade homogênea. As dinâmicas da vida e do trabalho mobilizam e possibilitam forças de criação e resistência que permitem sua singularização. Ao mesmo tempo, aportam às chefias intermediárias dilemas até então insuspeitados. 


\section{Referênclas}

ACHUTTI, Luiz Eduardo Robinson. Fotoetnografia da Biblioteca Jardim. Porto Alegre: Editora da UFRGS/Tomo Editorial, 2004.

BARROS, Regina Benevides. Grupo: a afirmação de um simulacro. Porto Alegre: Sulina, 2007.

BAUMAN, Zygmunt. Vida Líquida. Rio de Janeiro: Jorge Zahar Editores, 2007.

Vidas desperdiçadas. Rio de Janeiro: Jorge Zahar Editores, 2005

Comunidade. Rio de Janeiro: Jorge Zahar Editores, 2003.

CAMPOS, Gastão Wagner de Sousa. Um método para análise e co-gestão de coletivos. São Paulo: Editora Hucitec, 2005.

CAMPOS, Gastão Wagner de Sousa; AMARAL, Márcia Aparecida do. A clínica ampliada e compartilhada, a gestão democrática e redes de atenção como referenciais teórico-operacionais para a reforma do hospital. Ciência \& Saúde Coletiva, Rio de Janeiro, v. 12, n. 4, 2007. P.849-859.

CARAPINHEIRO, Graça. Saberes e poderes no hospital. $4^{\mathrm{a}}$. Ed. Porto: Edições Afrontamento, 2005.

CECÍLIO, Luiz Carlos de Oliveira. O desafio de qualificar o atendimento prestado pelos hospitais públicos. In: MERHY, Emerson Elias; ONOCKO, Rosana (Orgs.). Agir em saúde: um desafio para o público. 2ª . Ed. São Paulo: Hucitec, 2002. p. 293-319.

Modelos tecno-assistenciais em saúde: da pirâmide ao círculo, uma possibilidade a ser explorada. Cadernos de Saúde Pública, v.13, n.3, Jul./Set. 1997, p.469-478.

DEJOURS, Christophe. Prefácio. In: LANCMAN, Selma; SZNELWAR, Laerte Idal (orgs). Christophe Dejours: da psicopatologia à psicodinâmica do trabalho. Rio de Janeiro: Editora Fiocruz, Brasília: Paralelo 15, 2004, p. 15-21.

A banalização da injustiça social. Rio de Janeiro: Editora FGV, 1999.

DUBOIS, Philippe. $O$ ato fotográfico e outros ensaios. $10^{\mathrm{a}}$. Ed. Campinas: Papirus, 2007.

DUSSAULT, Gilles. A gestão dos serviços públicos de saúde: características e exigências. Revista de Administração Pública, Rio de Janeiro, v.26, n.2, p. 8-19, abr./jun., 1992.

FOUCAULT, Michel. O nascimento do hospital. In: Microfísica do poder. $15^{\mathrm{a}}$. Ed. Rio de Janeiro: Edições Graal, 2000. p. 99-111.

GRISCl, Carmem Ligia lochins. Trabalho Imaterial. In: CATTANI, David; HOLZMANN, Lorena (orgs). Dicionário de Trabalho e Tecnologia. Porto Alegre: Editora da UFRGS, 2006. p. 327-329.

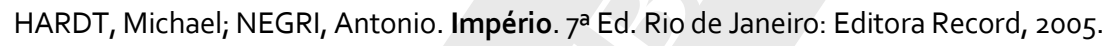

HARVEY, David. Condição pós-moderna: uma pesquisa sobre as origens da mudança social. $2^{a}$. Edição. São Paulo: Edições Loyola, 1993.

LAZZARATO, Maurízio; NEGRI, Antonio. Trabalho imaterial: formas de vida e produção de subjetividade. Rio de Janeiro: DP\&A, 2001.

LIMA, Maria Elizabeth Antunes. Os equívocos da excelência: as novas formas de sedução na empresa. Petrópolis: Vozes, 1995.

LIMA-GONÇALVES, Ernesto. Administração hospitalar: condicionantes internos e externos da atividade do hospital-empresa. RAEeletrônica, v.1, n. 2, Jul./Dez., 2002. 2op.

MAURENT, Vanessa. A experiência de si no trabalho nas ruas através da fotocomposição. 2005. Dissertação (Mestrado em Psicologia Social). Programa de Pós-Graduação em Psicologia Social e Institucional. Universidade Federal do Rio Grande do Sul. 2005. MINAYO, Maria Cecília de Souza (org.). Pesquisa social: teoria, método e criatividade. 18a Ed. Petrópolis: Editora Vozes, 2001. MINOTTO, Ricardo. A estratégia em organizações hospitalares. $2^{\text {a }}$. Ed. Porto Alegre: EDIPUCRS, 2003. Criando organizações eficazes. ${ }^{\text {a }}$. Ed. São Paulo: Editora Atlas, 2003. p. 212238. 
NEGRI, Antonio. Cinco lições sobre o império. Rio de Janeiro: DP\&A, 2003.

PASCHE, Dário Frederico. Gestão, subjetividade e saúde. 2003. Doutorado (Saúde Coletiva). Departamento de Medicina Preventiva e Social. Universidade Estadual de Campinas. Campinas. 2003.

PELBART, Peter. Vida capital: ensaios de biopolítica. São Paulo: Iluminuras, 2003.

PIRES, Denise. Reestruturação produtiva e trabalho em saúde no Brasil. São Paulo: Confederação Nacional dos Trabalhadores em Seguridade Social - CUT; Annablume, 1998.

PITTA, Ana. Hospital: dor e morte como ofício. $3^{\text {a }}$. Ed. São Paulo: Hucitec, 1994.

SENNETT, Richard. A cultura do novo capitalismo. Rio de Janeiro: Record, 2006.

A corrosão do caráter. $7^{\mathrm{a}}$. Ed. Rio de Janeiro: Record, 2003.

Autoridade. Rio de Janeiro: Record, 2001.

SILVA, Ana Lúcia Abrahão da. Produção de subjetividade e gestão em saúde: cartografias da gerência. 2004. Tese (Doutorado em Saúde Coletiva). Programa de Pós-graduação da Faculdade de Ciências Médicas. Universidade Estadual de Campinas, 2004.

STRANNEGÅRD, Lars. Sobre a foto da capa: "quase lá". In: DAVEL, Eduardo; MELO, Marlene Catarina de Oliveira Lopes (orgs.). Gerência em ação: singularidades e dilemas do trabalho gerencial. Rio de Janeiro: Editora FGV, 2005. p.15-17

TITTONI, Jaqueline; MAURENT, Vanessa. Imagens como estratégia metodológica em pesquisa: a fotocomposição e outros caminhos possíveis. Psicologia \& Sociedade, v.19, n.3, p. 33-38, 2007.

TITTONI, Jaqueline; NARDI, Henrique Caetano. Subjetividade e trabalho. In: CATTANI, David; HOLZMANN, Lorena (orgs). Dicionário de Trabalho e Tecnologia. Porto Alegre: Editora da UFRGS, 2006. p. 277-280.

WOOD JR, Thomaz; PAULA, Ana Paula Paes de. Pop-management: pesquisa sobre as revistas populares de gestão no Brasil. In: ENCONTRO NACIONAL DE PÓS-GRADUAÇÃO EM ADMINISTRAÇÃO, 26, 2002, Salvador, Anais... Salvador: 2002. CD -ROM.

YIN, Robert. Estudo de caso: planejamento e métodos. $2^{\mathrm{a}}$ Ed. Porto Alegre: Bookman, 2001.

\footnotetext{
${ }^{1}$ É importante salientar que o termo chefia, embora tenda ao desuso na atual literatura sobre gestão, será utilizado por ser o usual no hospital pesquisado. O termo gerente aparecerá como um equivalente de uso mais universal.

${ }^{2}$ Esta autora é portuguesa. O texto será mantido como no original.

${ }^{3}$ Pelo limite do presente artigo, não é possível apresentar de forma aprofundada este recurso metodológico. Cabe salientar, contudo, que existem diversos - e interessantes - trabalhos sobre o tema. Na presente pesquisa, utilizou-se como referência os textos de Tittoni e Maurent (2007), Dubois (2007) e Achutti (2004). Com relação à proposta do grupo, tomou-se como referencial Barros (2007).

${ }^{4}$ Refere-se às chefias da área da enfermagem no feminino, pois à época da pesquisa todas as unidades estavam sendo chefiadas por mulheres.
} 